\title{
Modificações nos atributos químicos de solo sob campo nativo submetido à queima
}

\author{
Changes of chemical attributes of a soil after burning \\ its native permanent pasture
}

\section{Danilo dos Santos Rheinheimer ${ }^{1}$ Júlio César Pires Santos ${ }^{2}$ Valesca Barros Barcelos Fernandes ${ }^{3}$ Álvaro Luis Mafra ${ }^{4}$ Jaime Antonio Almeida $^{2}$}

\section{RESUMO}

Estudos envolvendo a dinâmica de nutrientes no solo sob campo nativo submetido a queimas no Sul do Brasil são escassos. O presente trabalho tem por objetivo avaliar as modificações nos atributos químicos do solo oriundas da queima das pastagens nativas. O estudo foi desenvolvido em Lages - SC, num Cambissolo Húmico Alumínico, argiloso e com alto teor de matéria orgânica. Os tratamentos consistiram de duas áreas contíguas, uma de 5,06ha com pastejo e queima, e outra, de 3,4ha, somente submetida ao pastejo. A temperatura do solo, a $1 \mathrm{~cm}$ de profundidade, da área queimada, foi medida por sonda elétrica. As amostragens de solo, em três camadas $(0-2,2-5$ e $5-10 \mathrm{~cm})$, foram efetuadas 3 dias antes da queima, imediatamente após a queima e 30, 60, 90, 150, 220 e 350 dias após a queima, para o tratamento queimado; e 3 dias antes da queima, 90 e 220 dias após a queima, para o tratamento não queimado. Avaliaram-se o $\mathrm{pH}$ em água e os teores de $\mathrm{N}$-total, $\mathrm{N}-\mathrm{NO}_{3}{ }^{-}+\mathrm{NO}_{2}, \mathrm{~N}-\mathrm{NH}_{4}{ }^{+}, \mathrm{Ca}+\mathrm{Mg}, \mathrm{K}, \mathrm{Al}$ e P. A camada superficial do solo $(0-2 \mathrm{~cm})$ foi a que mostrou ser mais sensível à ação do fogo, atingindo temperatura máxima de $70^{\circ} \mathrm{C}$ aos 4 minutos. Nessa camada, logo após a queima, ocorreu aumento nos teores de nitrato e diminuição nos teores de amônio. Também a queima aumentou os teores de $\mathrm{K}, \mathrm{Ca}+\mathrm{Mg}$ $e$ os valores de $\mathrm{pH}$ e diminuiu os teores de $\mathrm{Al}^{+3}$. De um modo geral, todos os atributos químicos do solo avaliados tenderam aos valores originais a partir dos 90 dias após a queima.
Palavras-chave: forragem, queima de campo nativo, disponibilidade, nutrientes.

\section{SUMMARY}

Studies done with the soil nutrient dynamics pastures on native fields burned in the South of Brazil are rare. The present work has the objective of evaluating the changes on the soil chemical attributes originated after burning native permanent pasture. The work was developed in Lages - SC, Brazil in a Haplumbrept, on a clay soil and with high percentage of organic matter. The treatments consisted of two adjacent areas, one with 5.06ha. under grazing and burned over and another with 3.5ha submitted to grazing only. The soil temperature, at $1 \mathrm{~cm}$ of depth, of the burned area was measured by electric drilling. The soil samples, in three layers (0-2, 2-5 and $5-10 \mathrm{~cm}$ ), were taken 3 days before the burning, immediately after the burning and 30, 60, 90, 150, 220 and 350 days after the burning, for the burned treatment; and 3 days before the burning, 90 and 220 days after the burning, for the non-burned treatment. The $\mathrm{pH}$ in water and the percentages of total $N, \mathrm{~N}$ $\mathrm{NO}_{3}^{-}+\mathrm{NO}_{2}, \mathrm{~N}_{-} \mathrm{NH}_{4}^{+}, \mathrm{Ca}+\mathrm{Mg}, \mathrm{K}, \mathrm{Al}$ and $\mathrm{P}$ were determined. The soil on the superficial layer $(0-2 \mathrm{~cm})$ was the one which was

${ }^{1}$ Engenheiro Agrônomo, Doutor,Bolsista CNPq., Professor Adjunto no Departamento de Solos, Universidade Federal de Santa Maria, 97105-900, Santa Maria, RS. E-mail: danilo@ccr.ufsm.br. Autor para correspondência.

${ }^{2}$ Engenheiro Agrônomo, Doutor, Professor IV no Departamento de Solos, Universidade do Estado de Santa Catarina, Lages, SC. ${ }^{3}$ Biólogo, MSc.

${ }^{4}$ Engenheiro Agrônomo, Doutor, Bolsista Recém-doutor no Departamento de Solos, Universidade do Estado de Santa Catarina. Lages - SC. 
more susceptible to the burning action, reaching the maximum temperature of $70^{\circ} \mathrm{C}$, at four minutes after the burning. In this layer, the burning caused an increase in the $\mathrm{N}-\mathrm{NO}_{3}^{-}$percentages and decrease in the $\mathrm{N}-\mathrm{NH}^{+}$percentages. Also the burning increased the $\mathrm{K}, \mathrm{Ca}+\mathrm{Mg}$ and the $\mathrm{pH}$ values and it decreased the $\mathrm{Al}^{+3}$. Generally, all the soil chemical attributes, which were evaluated, demonstrated a tendency to return to the original values after 90 days of the burning.

Key words: forages, disponibility, nutrients, burning native permanent pasture.

\section{INTRODUÇÃO}

No Brasil, as queimas ocorrem praticamente em todo o território, motivadas por fatores locais. A maioria das queimadas é provocada direta ou indiretamente pelo homem, quer para abrir novas fronteiras agrícolas, quer para obter pastagem fresca para o gado (COUTINHO, 1990). As queimadas de maior vulto reportam-se à região Amazônica, à região dos cerrados e aos campos do sul do país.

A queima de campos do sul do país aparece como forma de manejo das pastagens, sendo amplamente difundida em Santa Catarina e no Rio Grande do Sul. O fogo vem sendo utilizado há tanto tempo nesta região que chega a ser uma questão cultural. Talvez neste ponto se encontre o grande desafio de trabalho nesta área: os pecuaristas queimam o campo não só pelo resultado rápido que acreditam ter, mas também porque esta é praticamente a única forma que aprenderam a utilizar para o manejo do pasto, durante a época da seca.

O processo de queima realizado em pastagens nativas no sul do país é realizado para destruir o material seco acumulado, para aceleração do rebrote na primavera e para aumentar a disponibilidade de nutrientes imediatamente após a queima. Os maiores questionamentos que envolvem todo o processo relacionam-se à durabilidade do fenômeno, ou seja, se, em primeiro lugar, este aumento de nutrientes é real ou apenas instantâneo, e, em segundo lugar, se o ecossistema como um todo consegue manter-se em algum estado de equilíbrio.

Em termos gerais, as temperaturas no interior do solo não se elevam muito durante uma queima, mas a perda de água pode ser muito grande. Geralmente, o fogo não afeta os nutrientes nas camadas inferiores a $2 \mathrm{~cm}$ do solo (DeBANO \& CONRAD, 1978). Dentre os nutrientes, o nitrogênio é o mais estudado, e seu ciclo se modifica com a queima, aumentando a quantidade de N amoniacal (DeBANO et al, 1979), o qual é nitrificado rapidamente, podendo ser lixiviado. A recuperação das plantas depois da queima depende em parte das formas de $\mathrm{N}$ que permanecem disponíveis. $\mathrm{O}$ fogo pode provocar pequenas perdas de $\mathrm{N}$ por volatilização (MROZ et al., 1980).

A queima da vegetação morta enriquece o solo da camada superficial na maioria dos nutrientes, por acelerar a mineralização, quer química ou biológica. Comparando áreas queimadas, com ou sem influência de pastejo, no Kansas, OWENSBY \& WYRILL (1973) descreveram aumentos nas concentrações de $\mathrm{Ca}, \mathrm{Mg}$ e K , diminuição de $\mathrm{N}$ na camada de $3 \mathrm{~cm}$ de solo e nenhuma mudança para o $\mathrm{P}$.

Em curto prazo, o fogo torna-se um agente de mineralização, aumentando a disponibilidade de nutrientes para o crescimento das plantas, especialmente em profundidades menores que $0,5 \mathrm{~cm}$ de solo, devido as cinzas com alta concentração de $\mathrm{P}, \mathrm{K}$ e $\mathrm{Ca}$ (COUTINHO, 1990; KAUFFMAN et al., 1994). Além do enriquecimento do solo do cerrado, provocado por ação das cinzas, houve um decréscimo no teor de Al, logo após a queima, fato que também pode ser encarado como benéfico (COUTINHO, 1990). Em estudo realizado na região de Guaíba - RS, EGGERS (1991) observou que a queima aumentou a matéria orgânica, K, Ca e Mg e diminuiu o $\mathrm{pH}$. Ressalta, contudo, que tais diferenças apresentaram-se confusas em alguns pontos de amostragem, não definindo um comportamento estável de deterioramento ou melhoria da fertilidade do solo. Além disso, quando associadas aos dados da vegetação, não foram determinadoras de qualquer tipo de alteração marcante.

O presente trabalho teve por objetivo avaliar as modificações nos atributos químicos do solo oriundas da queima de um campo nativo.

\section{MATERIAL EMÉTODOS}

O experimento foi conduzido em Lages, onde há queimas periódicas no final do inverno como prática de manejo de pastagens nativas. Lages localiza-se na região sudoeste do estado de Santa Catarina, no planalto serrano, a uma altitude média de $937 \mathrm{~m}$ acima do nível do mar, com clima mesotérmico úmido e com verão ameno (Cfb, conforme a classificação de Köpen).

O solo da área experimental é classificado como Cambissolo Húmico alumínico, pouco profundo, com horizonte A espesso, alto teor de matéria orgânica, textura argilosa, baixa saturação com bases e alta com Al trocável.

Os tratamentos consistiram de duas áreas contíguas, uma de 5,06ha na qual houve pastejo e queima, e outra, de 3,4ha, somente submetida ao pastejo. A área não era queimada há aproximadamente 20 anos. A queima foi realizada em 26/08/93. 
A determinação da temperatura do solo da área queimada foi feita por sonda elétrica, determinando-se a intensidade e o tempo de permanência de calor no solo a uma profundidade de $1 \mathrm{~cm}$.

As amostras de solo foram coletadas em cinco pontos em cada tratamento, com quatro subamostras por ponto. A coleta foi feita com tubos de PVC introduzidos até $10 \mathrm{~cm}$ de profundidade no perfil do solo. As amostras foram subdivididas em três camadas $(0-2,2-5$ e $5-10 \mathrm{~cm})$, secas em estufa e submetidas a análises químicas seguindo os métodos descritos por TEDESCO et al. (1995). As amostragens de solo foram efetuadas 3 dias antes da queima, imediatamente após a queima e 30 , $60,90,150,220$ e 350 dias após a queima, para o tratamento queimado; e 3 dias antes da queima, 90 e 220 dias após a queima, para o tratamento não queimado.

Foram realizados dois tipos de análise estatística, sendo num nível de ordenação e outro com testes de aleatorização. As análises de ordenação utilizadas foram do tipo coordenadas principais, sendo que a medida de semelhança utilizada para a confecção da matriz foi à distância euclidiana(ORLÓCI \& PILAR, 1989). Na análise de coordenadas principais, para a verificação de possíveis contrastes entre a área queimada e a área não queimada, foram realizadas análises só para unidades queimadas, e depois só para unidades não queimadas. Os testes de hipótese realizados foram de aleatorização e são válidos para todos os tipos de amostra, independentemente de sua forma de seleção (HULBERT, 1984). Para o teste de aleatorização foram considerados 3 blocos, um para cada camada de solo. As épocas do ano foram consideradas como fatores, avaliandose o comportamento da área total por comparação.

\section{RESULTADOS E DISCUSSÃO}

Ocorreu um aumento nos teores de N-total logo depois da queima, diminuindo nos meses subseqüentes, inclusive não retornando às concentrações naturais no fim do período de um ano (Figura 1). Estas modificações, entretanto, só ocorreram na camada superficial do solo $(0-2 \mathrm{~cm})$. As possíveis perdas de nitrogênio por volatilização podem ser compensadas por ganhos estimulados por um aumento na atividade bacteriana do solo logo após um período de queima (JORGENSEN \& WELLS, 1971; CHRISTENSEN, 1973; DeBANO et al., 1979; MROZ et al., 1980). Para uma avaliação mais completa do comportamento do ciclo do $\mathrm{N}$ em uma área queimada, entretanto, é interessante analisar o comportamento do $\mathrm{N}$ amoniacal e dos nitritos e nitratos.

Logo após a queima, especialmente na camada superficial, há um decréscimo na concentração de $\mathrm{N}$-amônio, seguido de um súbito aumento cerca de 60 dias após a queima (Figura 1). Este comportamento parece estar de acordo com um aumento nos processos de nitrificação,

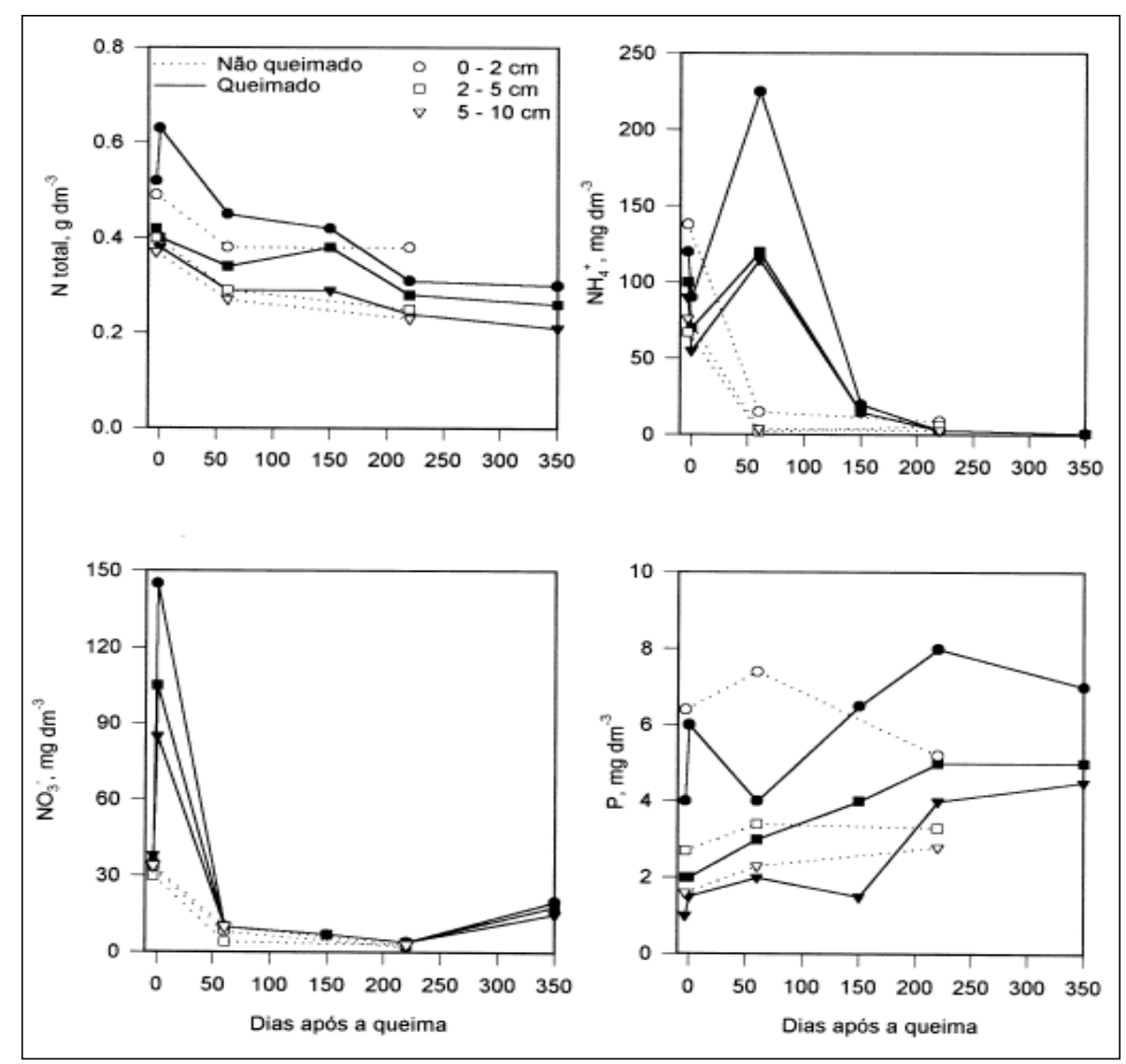

Figura 1 - Teor de nitrogênio total, N-nitrato e fósforo em diferentes camadas de solo sob campo nativo em função da queima e do período de amostragem.

Ciência Rural, v. 33, n. 1, jan-fev, 2003. 
estimulados pelo calor da queima: o teor do substrato amônia diminui logo após a queima, havendo um incremento posterior, correspondendo aos processos de mineralização subseqüentes (MROZ et al., 1980). No decorrer do período analisado, os níveis de $\mathrm{N}$-amônio nas unidades queimadas voltaram a valores próximos do controle.

A camada superficial $(0-2 \mathrm{~cm})$ não é a que possui maiores quantidades de nitritos e nitratos. Entretanto, com a queima, a concentração destes nutrientes aumenta abruptamente nesta camada, chegando a valores muito maiores que nas outras, apesar do aumento ser geral para todo o perfil analisado (Figura 1). Este aumento ocorre em seguida à queima, confirmando as tendências evidenciadas pela análise do comportamento do $\mathrm{N}$-amônio. Cerca de 60 dias após a queima a quantidade é diminuída, também abruptamente, a valores semelhantes aos do controle, concomitantemente ao aumento na quantidade de $\mathrm{N}$-amônio, revelando um aumento nos processos de amonificação.

Apesar de o teor de $\mathrm{P}$ no solo ser menor na área queimada do que na área não queimada no começo do período analisado, observa-se um aumento na sua concentração subseqüente à queima, seguido de um decréscimo abrupto aos 60 dias após a queima, na camada superficial (Figura 1). Este aumento parece estar vinculado à formação das cinzas, com conseqüente maior disponibilidade às plantas e maior utilização pelas mesmas no período final do inverno, quando rebrotame acabam reabsorvendo mais nutrientes do solo (BALDANZI, 1955; SERTSU \& SANCHEZ, 1978; TEIXEIRA \& SCHUBART, 1988; COUTINHO, 1990; KAUFFMAN et al., 1994).

O solo onde a vegetação foi queimada apresentava valores de $\mathrm{K}$ muito mais elevados que as unidades não queimadas, e, logo após a queima, houve um aumento nas concentrações em todas as camadas, mas muito pronunciado na camada superficial, seguido de um abrupto decréscimo após a queima que perdurou até os 60 dias. De modo similar, a queima provocou aumentos nas concentrações de $\mathrm{Ca}$ e de $\mathrm{Mg}$, porém rapidamente retornaram aos valores iniciais (Figura 2). O aumento na concentração desses cátions está vinculado à liberação de óxidos nas cinzas, estando de acordo com que acontece em outros ambientes (BALDANZI, 1955; OWENSBY \& WYRILL,1973; TEIXEIRA \& SCHUBART, 1988; COUTINHO, 1990; EGGERS, 1991; KAUFFMAN et al., 1994). A rápida disponibilidade destes nutrientes, no período subseqüente a invernos rigorosos, está diretamente relacionada ao crescimento rápido e vigoroso das plantas - objetivo primordial da queima na região.

A queima diminuiu a concentração de $\mathrm{Al}^{+3} \mathrm{em}$ todas as camadas amostradas, com posterior elevação a partir dos 90 dias após a queima. No final do período amostrado, entretanto, as concentrações permanece-

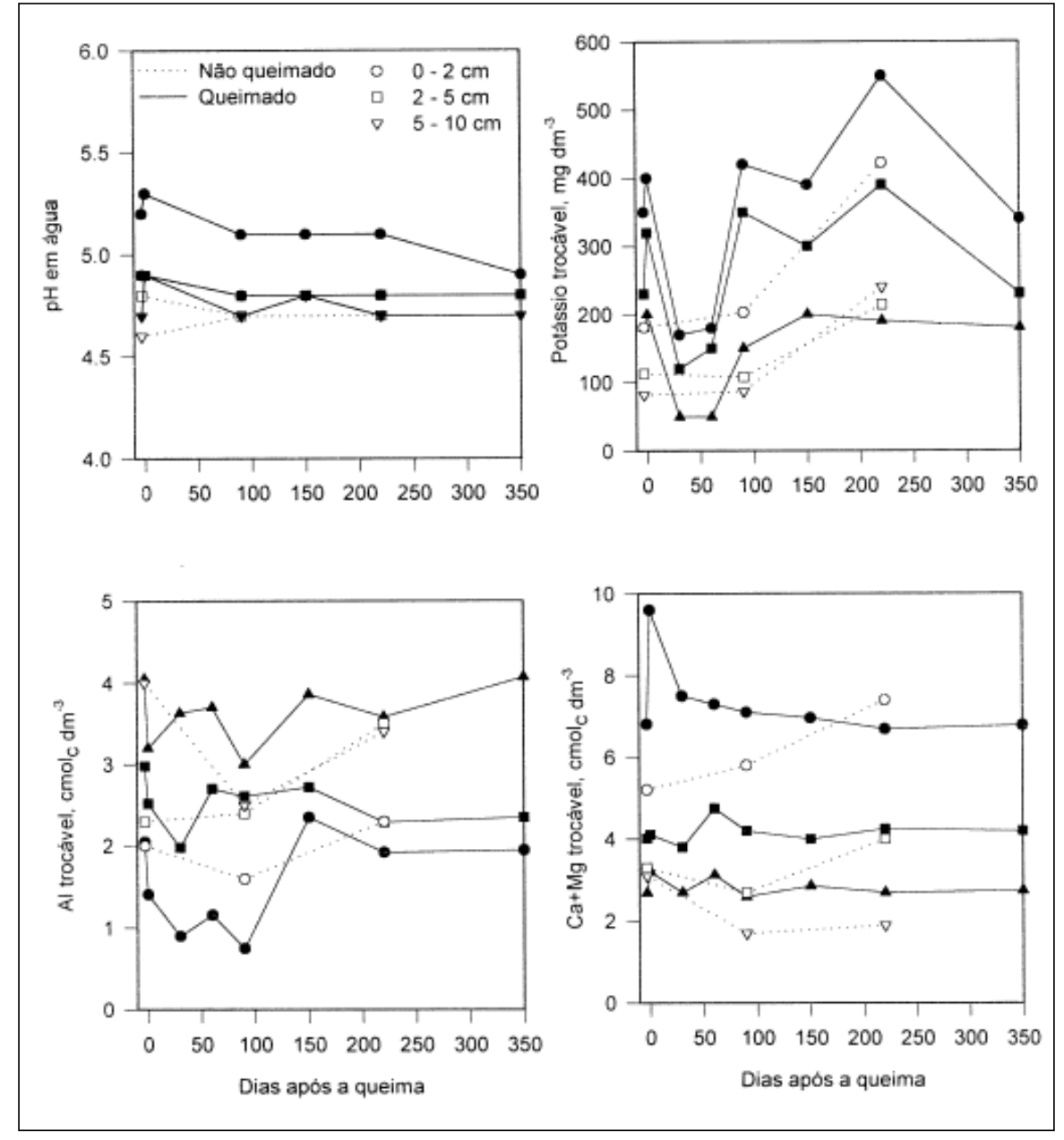

Figura 2 - pH em água, potássio, alumínio e cálcio+magnésio trocáveis em diferentes camadas de solo sob campo nativo em função da queima e do período de amostragem

Ciência Rural, v. 33, n. 1, jan-fev, 2003. 


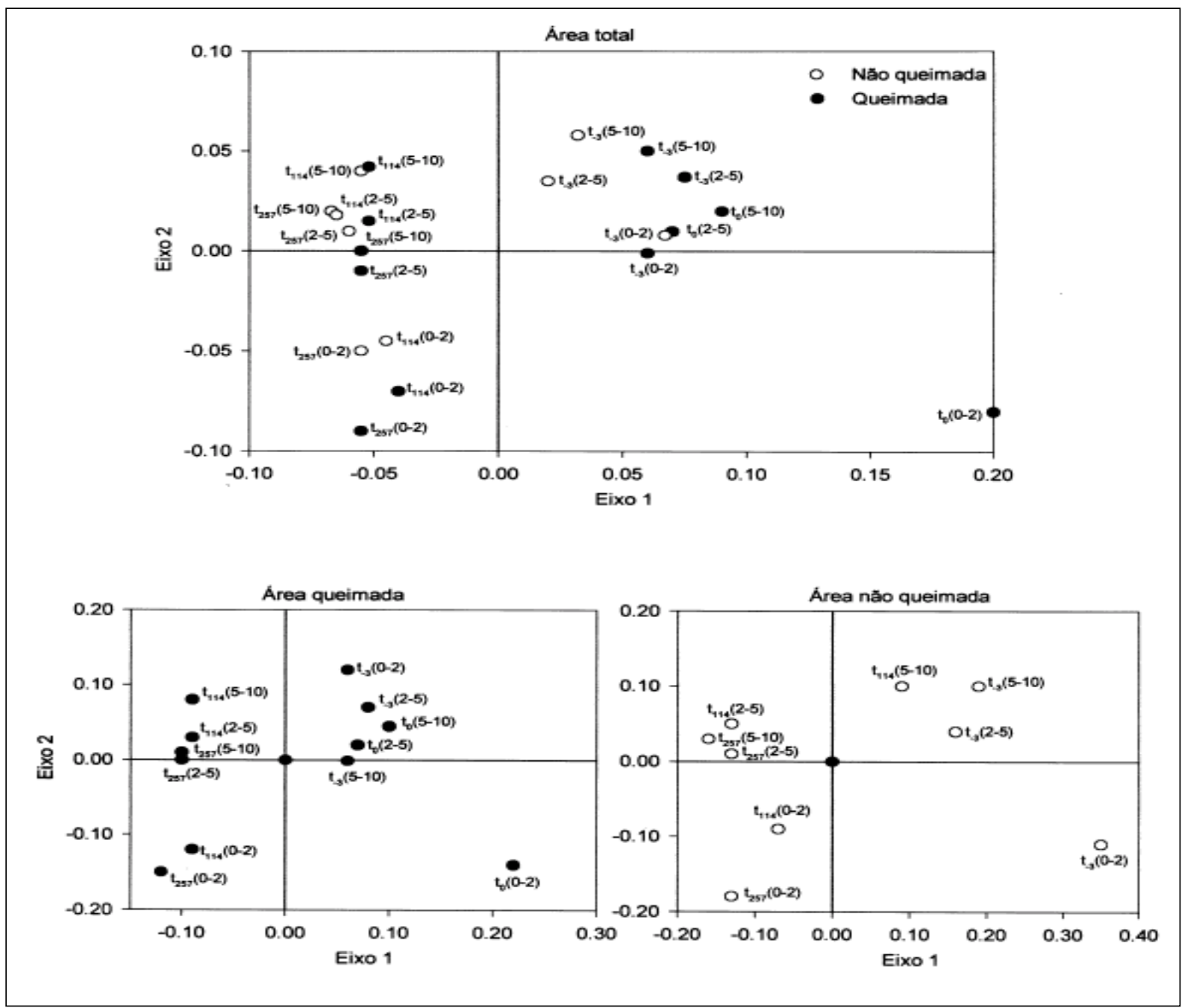

Figura 3 - Comportamento dos atributos químicos do solo segundo análise das coordenadas principais em função da queima e do período de amostragem.

ram mais baixas nas unidades amostrais queimadas (Figura 2). A diminuição na quantidade de $\mathrm{Al}$ ocorre também em outros ecossistemas brasileiros (TEIXEIRA \& SCHUBART, 1988; COUTINHO, 1990).

O solo da área cujo campo nativo foi queimado apresentou uma ligeira elevação do $\mathrm{pH}$, especialmente na camada superficial, que se manteve ao longo do ano. Depois de 220 dias da queima, entretanto, houve um decréscimo do $\mathrm{pH}$ da área queimada não acompanhada pelo controle. $\mathrm{O}$ pH das camadas mais profundas do solo não se modificou com a queima (Figura 2). Apesar de a variação no $\mathrm{pH}$ estar vinculada ao tipo de ambiente onde ocorreaqueima(BALDANZI, 1955; TEIXEIRA\&SCHUBART, 1988; EGGERS, 1991), neste caso, considerando a pequena variação observada e o tipo de solo, com grande capacidade de tamponamento (OLIVEIRA et al, 1992), a queima não parece interferir no sistema solo.
A figura 3 apresenta o período que antecedeu a queima e logo após a queima (mês de agosto) separado dos demais, tanto nas unidades queimadas quanto nas não queimadas, revelando um padrão de distribuição motivado provavelmente pelas baixas temperaturas do inverno. Os períodos de 90 e 220 dias após a queima apresentam-se reunidos, para as duas parcelas, demonstrando que as modificações nas concentrações de nutrientes nas camadas mais profundas do que $2 \mathrm{~cm}$ possam ter ocorrido logo após a queima, não permaneceram ao longo do ano. Entretanto, a unidade de amostra representativa logo após a queima, na camada $0-2 \mathrm{~cm}$, aparece separada das demais, localizando-se no extremo positivo do primeiro eixo e no extremo negativo do segundo eixo - fato que parece estar demonstrando as alterações sofridas nas concentrações de alguns nutrientes motivadas pelo fenômeno da queima. 
As variáveis N-total, $\mathrm{N}-\mathrm{NH}_{4}^{+}$e $\mathrm{N}-\mathrm{NO}_{3}{ }^{-}+\mathrm{NO}_{2}$ apresentam uma correlação positiva com a unidade amostrada logo após a queima (primeiro eixo), provavelmente indicando maiores modificações nestes nutrientes, durante o período analisado. No segundo eixo, as variáveis $\mathrm{Ca}+\mathrm{Mg}, \mathrm{P}$ e K apresentam uma correlação negativa, enquanto a variável $\mathrm{Al}$ apresenta uma correlação positiva, caracterizando um aumento nas concentrações dos primeiros nutrientes citados em contrapartida da diminuição de $\mathrm{Al}$.

Analisando-se as unidades queimadas e não queimadas separadamente, nota-se um padrão de distribuição motivado pelas estações do ano (Figura 3). O fenômeno da queima não parece atuar de forma modificadora, ou se o faz, é por um período curto de tempo, havendo um restabelecimento das concentrações dos nutrientes do solo ao final do período analisado.

Considerando a análise para as unidades não queimadas, percebe-se uma correlação positiva das variáveis $\mathrm{N}$-total, $\mathrm{N}-\mathrm{NH}_{4}^{+} \mathrm{e} \mathrm{N}-\mathrm{NO}_{3}^{+}+\mathrm{NO}_{2}$ no período em que a vegetação de parte da área experimental foi queimada (agosto - primeiro eixo). Esta relação pode representar um acúmulo natural de alguns nutrientes no solo, durante o inverno, quando a absorção pelas plantas é diminuída, revelando que as modificações ocorridas no ciclo do nitrogênio neste período amostrado não devem ser apenas motivadas pela queima. A variável Al apresenta uma correlação positiva com o segundo eixo, enquanto as demais apresentam uma correlação negativa (Figura 3).

A unidade queimada revela um padrão de distribuição semelhante ao do gráfico geral, no qual, logo após a queima, na camada $0-2 \mathrm{~cm}$, aparece separado dos demais (Figura 3). Revelam-se pequenas variações ocorridas no $\mathrm{pH}$, motivadas pela queima, uma vez que a variável correspondente possui uma fraca correlação com qualquer um dos eixos. Considerando os contrastes referentes à área não queimada, verifica-se a presença de diferença significativa entre o mês logo após a queima e as avaliações realizadas aos 90 e 220 dias após a queima, confirmando que, provavelmente, as mudanças ocorridas nas concentrações dos nutrientes são de natureza sazonal (Figura 3). Comparando-se tais resultados com aqueles observados na área queimada, nota-se que não existem diferenças significativas entre as coletas efetuadas antes e logo após a queima, mas sim destas duas coletas em relação às demais, 90 e 220 dias após. Dessa forma, considerando-se as variações dos nutrientes analisados como um todo no sistema solo, ao longo de um ano, a queima não provoca perturbação significativa.

De forma geral, a camada superficial foi a que demonstrou maior sensibilidade à atuação do fogo. A medição da temperatura do solo revelou que, depois de ateado o fogo, houve uma demora de 4 minutos para atingir a temperatura máxima, que foi de aproxima- damente $70^{\circ} \mathrm{C}$, voltando aos padrões normais em 3 minutos. A queima neste ambiente, em condições favoráveis de vento, portanto, não parece promover temperaturas muito danosas para o sistema solo, justificando as maiores variações na camada superficial. Mesmo em outros ambientes, o fogo rápido não afeta as camadas mais profundas do perfil do solo (DeBANO \& CONRAD, 1978; MALLIK et al., 1984; COUTINHO, 1990).

\section{CONCLUSÕES}

A camada superficial do solo $(0-2 \mathrm{~cm})$ é a mais sensível à ação do fogo, atingindo temperatura máxima de $70^{\circ} \mathrm{C}$ aos 4 minutos. Nessa camada, a queima provoca aumento nos teores de N-nitrato e diminuição nos teores de $\mathrm{N}$-amônio. A queima aumenta os teores de potássio, cálcio + magnésio e os valores de $\mathrm{pH}$ e diminui os teores de alumínio trocável. De um modo geral, todos os atributos químicos do solo avaliados tendem aos valores originais a partir dos 90 dias após a queima.

\section{REFERÊNCIAS BIBLIOGRÁFICAS}

BALDANZI, G. Efeito das queimadas sobre a fertilidade do solo e a produção de culturas, Pelotas, RS, 1955. In: CONGRESSO BRASILEIRO DE CIÊNCIA DO SOLO, 5., 1955. Pelotas, RS. Anais... Pelotas : SBCS, 1955. p.47.

CHRISTENSEN, N. Fire and the nitrogen cycle in California Chaparral. Science, Londres, v.181, p.66-68, 1973.

COUTINHO, L.M. O cerrado e a ecologia do fogo. Ciência Hoje, Brasília, v.12, n.68, p.22-30, 1990.

DeBANO, L.; CONRAD, C.E. The effect of fire on nutrients in a Chaparral ecosystem. Ecology, Oxford, v.59, n.3, p.489497, 1978.

DeBANO, L.; EBERLEIN, G.; DUNN, P. Effects of burning on Chaparral soils: I - Soil nitrogen. Soil Science Society of American Journal, Madison, v.43, n.3, p.504-509, 1979.

EGGERS, L. Ação do fogo em uma comunidade campestre, em bases fitossociológicas. 1991. 136f. Dissertação (Mestrado em Ecologia) - Curso de Pós-graduação em Ecologia, Universidade Federal do Rio Grande do Sul.

HULBERT, S.H. Pseudoreplication and the desing of ecological field experiments. Ecological Monographs, v.54, n.2, p.187$211,1984$.

JORGENSEN, J.; WELLS, C. Apparent nitrogen fixation in soil influenced by prescribed burning. Soil Science Society of American Proceeding, Madison, v.35, n.5, p.06-810, 1971.

KAUFFMAN, D.; CUMMINGS, D.; WARD, D. Relationships of fire, biomass and nutrient dynamics along vegetation gradient in the Brazilian Cerrado. Journal of Ecology, Oxford, v.82, n.3, p.519-531, 1994. 
MALLIK, A.; GIMINGHAM, C.; RAHMAN, A. Ecologic effects of heather burning - I. Water infiltration, moisture retention and porosity of surface soil. Journal of Ecology, Oxford, v.72, n.4, p.767-776, 1984.

MROZ, G. et al. Effects of fire on nitrogen in forest floor horizons. Soil Science Society of American Journal, Madison, v.44, n.2, p.235-242, 1980.

OLIVEIRA, J. B.; JACOMINE, P.; CAMARGO, M. Classes gerais de solos do Brasil: guia auxiliar para seu reconhecimento. 2. ed. Jaboticabal : FUNEP, 1992. 201p.

ORLÓCI, L.; PILLAR, V. On sample size optimality in ecosystem survey. Biometrie-Praximetrie, Bruxelas, v.29, N.1, p.173-184, 1989 .
OWENSBY, C.; WYRILL, J. Effects of range burning on Kansas Flint Hills Soil. Journal of Range Management, v.26, n.3, p.185-188, 1973.

SERTSU, S.; SANCHEZ, P. Effect of heating on some change in souil properties in relation to na Ethiopian Land management. Soil Science Society of American Journal, Madison, v.42, n.6, p.940-944, 1978.

TEDESCO, M.J. et al. Análise de solo, plantas e outros materiais. 2 ed. Porto Alegre : Departamento de Solos da UFRGS, 1995. 174 p. (Boletim Técnico, 5).

TEIXEIRA, L.; SCHUBART, H. Mesofauna do solo em áreas de floresta e pastagens na Amazônia Central. Belém : EMBRAPA-CPATU, 1988. (Boletim, 95). 